\title{
Luciano Berio, restaurador: análise de Rendering per orchestra (1988-90)
}

PAULO MIRANDA

Doutorado, em andamento, na Universidade do Estado de São Paulo - Música/Teoria e Práxis do Processo Criativo (UNESP-PPGMUS). Mestrado em Artes - subárea Música (UFU-PPGARTE). Bacharelado em Música/Flauta transversal (UFU-IA). Desde 2012 é servidor técnico-administrativo do Setor de Multimeios do Sistema de Bibliotecas-UFU. Desenvolveu pesquisas na área de análise musical sobre importantes obras da literatura desse instrumento no século XX, tendo publicado trabalhos sobre Voice, de T. Takemitsu; Jupiter, de P. Manoury; Synchronisms 1, de M. Davidovsky; e Kathinkas Gesang, de K. Stockhausen. (<http://lattes.cnpq.br/1369400461882363>).

AFILIAÇÃO: Universidade Federal de Uberlândia, Uberlândia, Minas Gerais. 


\section{- RESUMO}

Em Rendering, Berio propôs-se restaurar os esboços da décima sinfonia que ocupou Schubert em suas últimas semanas de vida. Este artigo investiga sua atuação sobre o texto musical schubertiano, desvelando o profícuo engajamento do compositor italiano com as vanguardas artísticas do século XX e, ao mesmo tempo, seu diálogo com importantes realizações da tradição musical. Evitando uma intervenção fantasiosa, a obra orienta-se pelas "linhas da restauração moderna de afrescos que visam reviver as cores antigas sem, contudo, disfarçar o dano causado pelo tempo" (BERIO, 1989). A hipótese norteadora é que os procedimentos escriturais adotados por Berio são implicitamente engajados nos preceitos da Teoria da Restauração (1963) de Cesare Brandi, ícone do restauro crítico italiano. As análises das estratégias composicionais do primeiro movimento de Rendering esclarecem, de um lado, o trabalho sobre a orquestração e contraponto visando reviver as cores de Schubert e, de outro, a intervenção sobre as lacunas entre os fragmentos através de uma argamassa musical tipicamente beriana.

\section{PALAVRAS-CHAVE}

Luciano Berio, Rendering, análise musical, restauração, Cesare Brandi.

\section{ABSTRACT}

By Rendering, Berio intended to restore Schubert's tenth symphony, based on the sketches of that symphony that kept Schubert busy in his final days. This paper examines Berio's work on Schubertian musical text, uncovering the productive commitment of the Italian composer to the 20th century avant-garde art and, at the same time, his references to important works in music tradition. The composer avoids a fanciful intervention and follows the "lines of the modern restoration of frescoes that aims at reviving the old colours without however trying to disguise the damage that time has caused" (BERIO, 1989). Our guiding hypothesis suggests that Berio's writing methods are implicitly committed to the principles of Cesare Brandi's Theory of Restoration (1963), who is an icon of the Italian critical restoration. The analyses of the methods of composition of Rendering first movement reveal the work on orchestration and counterpoint on the one hand, aiming at refreshing the colors of Schubert, and, on the other, the intervention in the gaps between the fragments by means of a musical cement typical of Berio.

\section{KEYWORDS}

Luciano Berio, Rendering, musical analysis, restoration, Cesare Brandi. 
A obra do compositor Luciano Berio (1925-2003), um dos expoentes da geração pós-weberniana, revela uma relação oblíqua entre a experimentação escritural pós-serial e uma aguçada consciência da música do passado. Esse traço poético beriano decorre da negação de um grau zero na música, premissa de seu pensamento (BERIO, 1985), e se efetiva por uma série de encontros com a tradição musical.

Profundamente afetado por essa estrutura arquetípica, Berio assume sua "tendência em trabalhar com a história, extraindo e conscientemente transformando 'minerais' históricos [...]" (BERIO, 1985, p. 66) (tradução nossa) ${ }^{1}$. Embora promovida por procedimentos composicionais diversos e guiada por considerações analítico-musicais, tal atitude pauta-se, sobretudo, na identificação afetiva de Berio com o repertório elegido².

Assim acontece com Rendering para orquestra, composta entre os anos de 1988 e 1990. Nessa peça, Berio expõe sua forte admiração por Franz Schubert (1797-1828) ao debruçar-se sobre fragmentos de uma décima sinfonia (D936a) ${ }^{3}$ que ocupou o compositor austríaco em suas últimas semanas de vida. Para ele, Rendering representa um "ato de amor por Schubert e pelos esboços de sua última sinfonia inacabada em Ré maior" (BERIO, 2006, p. 40) (tradução nossa) ${ }^{4}$.

Encantado pela complexidade dos fragmentos de Schubert, Berio propôs restaurá-los (BERIO, 2018). Ao transpor sua experiência composicional para o domínio das artes plásticas, o compositor nega uma atitude reconstrutiva em Rendering e orienta sua abordagem pelas "linhas da restauração moderna de afrescos que visam reviver as cores antigas sem, contudo, tentar disfarçar o dano causado pelo tempo, frequentemente deixando inevitáveis fragmentos vazios na composição" (BERIO, 1989) (tradução nossa) 5 .

Não se trata, pois, de uma reconstrução estrutural:

\begin{abstract}
Eu não queria substituir Schubert, como alguns já fizeram fingindo interpretar sua vontade: eu preferia realizar e interpretar instrumentalmente o que Schubert nos deixou. Então completei os dados frequentemente estenográficos dos esboços e preenchi as 'ausências' entre um fragmento e outro com uma espécie de 'argamassa' musical: em certo sentido operando como os restauradores de hoje, que cobrem com substâncias apropriadas as partes perdidas de pinturas antigas, evidenciando, assim, as ausências. O que fiz foi, em suma, um restauro, mas não estrutural. Eu não estava interessado em criar uma continuidade artificial nos esboços de Schubert [...]. (BERIO, 2017, p. 367) (tradução nossa) ${ }^{6}$
\end{abstract}

\footnotetext{
${ }^{1}$ No original: Tendency to work with history, drawing out and consciously transforming historical "minerals" (BERIO, 1985, p. 66).

2 A transcrição musical implica "identificação" e "generosidade" com o texto transcrito (BERIO, 2006, p. 35).

${ }^{3}$ A numeração das sinfonias de Schubert diverge a partir da sétima. Neste trabalho, considera-se a numeração utilizada por Berio e que segue a ordem consolidada pela editora Bretikopf \& Härtel (cf. GRIFELL, 2017).

${ }^{4}$ No original: act of love for Schubert and for his sketches for his last unfinished symphony in D major (BERIO, 2006, p. 40).

${ }^{5}$ No original: lines of the modern restoration of frescoes that aims at reviving the old colours without however trying to disguise the damage that time has caused, often leaving inevitable empty patches in the composition (BERIO, 1989).
} 
Implicitamente, sua fala reporta ao cenário artístico italiano do século XX, no qual o pensamento de Cesare Brandi (1906-1988) exerceu enorme influência. Discursando em prol de intervenções críticas, a teoria brandiana contribuiu para a sistematização das modernas práticas do restauro no pós-Segunda Guerra através, por exemplo, de suas observações referentes ao tratamento das lacunas. Assim, partindo-se de um entendimento transtextual da abordagem composicional de Berio $^{7}$, neste artigo delineia-se a hipótese de que Rendering implica em procedimentos escriturais estreitamente engajados nos preceitos da restauração propostos por Brandi.

As discussões fundamentam-se na inter-relação entre aspectos da poética musical de Berio e a principal contribuição teórica de Brandi, a Teoria da Restauração de $1963^{\circ}$. Por meio da análise do primeiro movimento da obra, elucidase a intervenção de Berio sobre os fragmentos D936a investigando suas duas estratégias escriturais adotadas: de um lado, o trabalho sobre a orquestração e contraponto visando reviver as cores antigas; de outro, a intervenção sobre as lacunas entre os fragmentos através de uma argamassa musical tipicamente beriana.

Fragmentos de uma sinfonia e a gênese de Rendering

No decurso de sua produção, são vários os trabalhos de Berio comprometidos com realizações de outros compositores da tradição ocidental9. Rendering exala o vigoroso senso histórico do mestre italiano, cujo caráter prospectivo dos esboços da derradeira sinfonia de Schubert tornou-se o principal estímulo do projeto. Para Berio, os fragmentos D936a oferecem indicativos de novos caminhos tomados por Schubert no gênero sinfônico, seu grande desafio composicional: "[...] o trabalho nesses esboços é visivelmente enorme e tudo parece olhar para o futuro" (BERIO, 2017, p. 255) (tradução nossa) ${ }^{10}$.

Em outubro de 1828, um mês antes de sua morte aos 31 anos de idade, Schubert iniciou a composição da décima sinfonia, sua última investida dentre tentativas que se reportam aos seus 14 anos $^{11}$. Porém, foi somente na ocasião da comemoração dos 150 anos da morte do mestre vienense em 1978 que tais fragmentos receberam seu devido reconhecimento. Conforme menciona Bodley

\footnotetext{
${ }^{6}$ No original: Non mi sono voluto sostituire a Schubert, come del resto alcuni hanno già fatto pretendendo di interpretarne la volontà: ho voluto piuttosto rendere e interpretare strumentalmente quanto Schubert ci ha lasciato. Cosí ho completato i dati spesso stenografici degli schizzi e ho riempito le 'assenze' fra un schizzo e l'altro con una sorta di 'gesso' musicale: in un certo senso operando come i restauratori di oggi, che ricoprono con sostanze apposite le parti perdute delle pitture antiche e mettono cosí, in evidenza, le assenze. Quello che ho fatto è insomma un restauro, non però strutturale. A me non interessava creare una continuità artificiale negli schizzi di Schubert [...] (BERIO, 2017, p. 367).

${ }^{7}$ Para Menezes (2015, p. 81) "deparamo-nos com transtextualidade na obra de Berio quando certos elementos, por mais simples que possam parecer, implicam reenvio a outras coisas pelo viés de uma referencialidade mais ou menos explícita". Este aspecto decorre do entendimento beriano da escritura musical enquanto Texto (BERIO, 2006): "um Texto multidimensional que está em evolução contínua [...]" (p. 49), "[...] como documento de um investimento e de um encontro de ideias e experiências" (p. 8).

${ }^{8}$ Cf. Brandi (2008).

${ }^{9}$ Destacam-se as transcrições de Monteverdi, Bach, Mozart, Boccherini, Brahms, Mahler, Verdi e Puccini.

${ }^{10}$ No original: [...] il lavoro su questi schizzi è visibilmente enorme e tutto sembra guardare al futuro (BERIO, 2017, p. 255).

11 Griffel (2017) menciona manuscritos datados de, aproximadamente, 1811, os quais atestam as primeiras tentativas de Schubert no gênero sinfônico.
} 
(2008), técnicas modernas de datação possibilitaram que uma compilação de 17 páginas de manuscritos fosse reconhecida como três sinfonias inacabadas, todas em Ré Maior: D615 (1818), D708a (1821) e D936a (1828).

Os rascunhos de 1828 contemplam três movimentos em escrita para piano, com poucas indicações de instrumentação. Trata-se de um movimento Allegro de abertura, um Andante e, por fim, um Scherzo, os quais ocupam 12 páginas no total (4, 2 e 6, respectivamente). Seu caráter fragmentário é verificável pela escassez das partes internas e da linha do baixo já na frase de abertura do tema principal (Figura 1) - presente na terceira lauda dos esboços, pois se refere a uma segunda versão dessa exposição ${ }^{12}$.
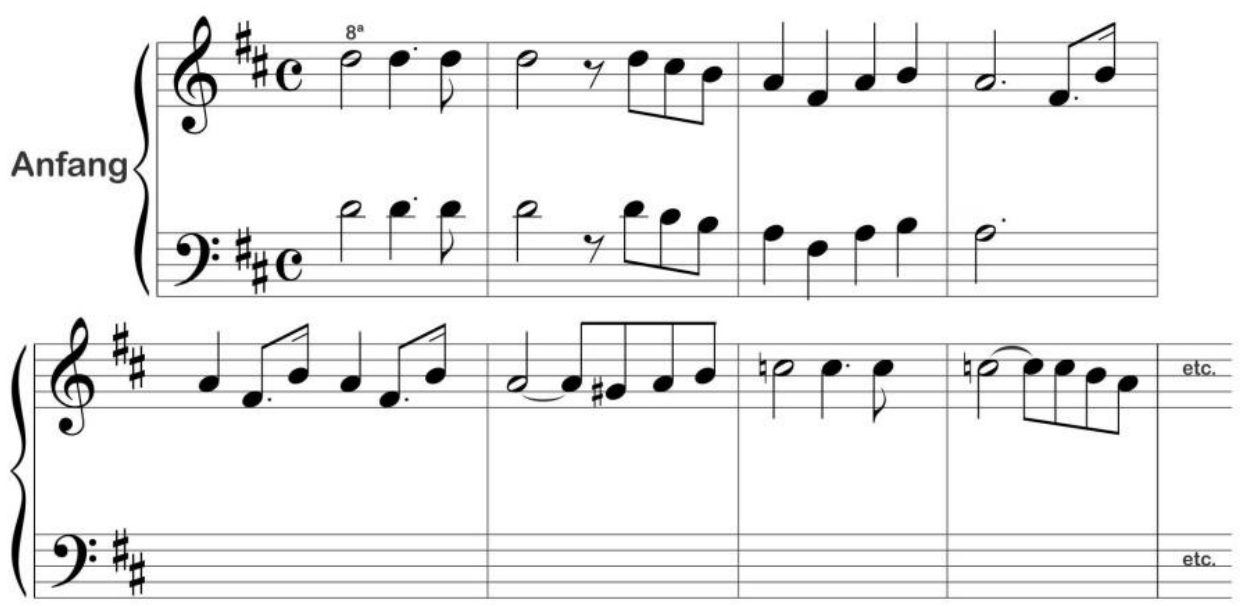

Figura 1. Frase de abertura do tema principal, primeiro movimento (D936a). Fonte: Adaptado de Berio (1989).

Embora inacabada, são notórias as experimentações escriturais dessa décima sinfonia. Assim como constatado por Berio, Griffel (2017) também atesta as novas direções schubertianas:

Se pudermos considerar as seis primeiras sinfonias de Schubert como vestígios do espírito clássico e a Sinfonia Inacabada e a Grande Sinfonia em Dó Maior como primeiras atualizações românticas do gênero sinfônico, então veremos nos esboços de 1828 a chegada de um romantismo puro-sangue no mundo da sinfonia (GRIFFEL, 2017, p. 270).

Ao longo dos três movimentos, distinguem-se inovações formais, harmônicas e tímbricas que distanciam Schubert da produção musical de seu tempo e se revelam sem precedentes no gênero sinfônico. No Allegro de abertura, destacam-se: a mudança de andamento na seção do desenvolvimento (Andante),

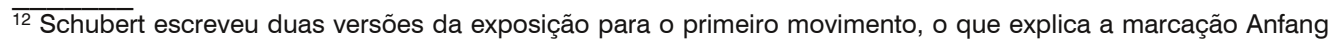
(Início) nesse trecho.
} 
iniciada por uma solene melodia nos trombones sob a região de Si bemol (i.e., modulação para uma tônica mediântica da tonalidade principal, traço harmônico abundantemente explorado na última fase do sistema tonal ${ }^{13}$ ); e a ausência de recapitulação, saltando do desenvolvimento para a coda final, novamente marcada por uma mudança de andamento (Presto).

O que surpreende no segundo movimento é seu lirismo temático circundado por um ambiente sonoro que remete à Mahler. Tal aspecto é amplamente observado por musicólogos, como Griffel (2017) que aproxima esse Andante ao movimento lento da primeira sinfonia de Mahler, escrita seis décadas depois. Berio (1989) também enxerga essa relação prospectiva: "o clima expressivo do segundo movimento é impressionante: parece habitado pelo espírito de Mahler" (tradução nossa) ${ }^{14}$. A estrutura do movimento é ambígua, remetendo tanto a uma variação dupla quanto a uma forma estrófica:

A repetição de dois temas em unidades recorrentes alude a uma variação dupla, contudo o aparecimento surpresa de um novo tema e a ausência de procedimentos de variação convencionais são atípicos a essa estrutura. Por outro lado, as mudanças sutis entre as diferentes unidades, para não mencionar a qualidade lírica dos temas, sugerem uma forma estrófica modificada (METZER, 2000, p. 101) (tradução nossa) ${ }^{15}$.

O último movimento (Scherzo) caracteriza-se por imbrincados contrapontos, o que supostamente reflete o contato de Schubert com o renomado mestre vienense de fugas, Simon Sechter ${ }^{16}$. Para Berio, "[...] esse movimento representa o contraponto mais complexo que Schubert escreveu. Talvez o próprio Beethoven raramente tenha alcançado esse tipo de refinamento no contraponto" (BERIO, 2017, p. 256) (tradução nossa) ${ }^{17}$.

O esquema formal desse movimento também apresenta explorações que ocasionam interessantes ambiguidades estruturais: a ênfase contrapontística e o caráter de Rondó entram em conflito com a designação dada por Schubert de Scherzo, aproximando-se mais de um Finale. Considerando-se a hipótese de que se trataria de uma fusão de ambos os caracteres, é possível presumir que, "nesse momento, Schubert acreditava que um bom finale sinfônico deveria estar apoiado em um intricado esquema contrapontístico" (GRIFFEL, 2017, p. 271).

\footnotetext{
$\overline{13}$ Para uma minuciosa exposição dos satélites mediânticos, sua utilização profética na música de Schubert, bem como a importância desse recurso harmônico na última fase do tonalismo, ver Menezes (2002).

${ }^{14}$ No original: the expressive climate of the second movement is stunning: it seems inhabited by Malher's spirit (BERIO, 1989).

${ }^{15}$ No original: The repetition of two themes in recurring units hints at a double variation, although the surprise appearance of a new theme and the absence of conventional variation procedures are atypical of that structure. On the other hand, the subtle changes between the different units, not to mention the lyrical quality of the themes, suggest a modified strophic design (METZER, 2000, p. 101).

${ }^{16}$ Newbould (1984) afirma que Schubert assistiu apenas a uma aula de Simon Sechter. De fato, há uma carta do professor de contraponto - datada de 21 de Agosto de 1857 - ao crítico musical Ferdinand Luib e que atesta que Schubert compareceu a uma aula em 4 de Novembro de 1828, duas semanas antes de seu falecimento (cf. BERIO, 2017, p. 258).

17 No original: [...] questo movimento rappresenta il contrappunto piú complesso che Schubert abbia mai scritto. Forse, lo stesso Beethoven ha raramente raggiunto questo tipo di raffinatezza nel contrappunto (BERIO, 2017, p. 256).
} 
Embora imediatamente interessado nos esboços D936A desde sua "redescoberta", o trabalho de Berio sobre os fragmentos dessa sinfonia iniciou-se somente em 1986. O primeiro projeto foi intitulado Opus $X$ e sua estreia se deu em 1988, sob a regência de Nikolaus Harnoncourt junto à orquestra residente do festival Schubertiade em Hohenems, Áustria. Submetida a revisão no ano seguinte, a obra passou a ter dois movimentos, já sob o título de Rendering. Mais uma vez conduzida por Harnoncourt em 1989 no Holland Festival, em Amsterdã, tal versão foi duramente criticada pelo compositor, acusando o maestro de não compreender os princípios subjacentes à obra, tampouco sua restauração empreendida sobre os fragmentos ${ }^{18}$. A partitura final em três movimentos foi estreada em abril de 1990 pela Royal Concertgebouw Orchestra sob a direção de Riccardo Chailly, a quem a obra é dedicada.

\section{Uma restauração crítica de Schubert: paralelos entre Berio e Brandi}

Em Rendering, é assumida uma dupla autoria: Schubert-Berio. Essa duplicidade exprime-se já no título da obra, aludindo a uma gama de significados associados à intenção artística de Berio, dentre os quais o da interpretação dos rascunhos de Schubert, manipulando-os conforme sua necessidade composicional; o da tradução desses fragmentos sinfônicos do passado para um estilo e linguagem modernos; e o da aplicação de argamassa sobre a superfície fragmentada schubertiana.

Sua abordagem enquanto restaurador enfatiza uma intervenção crítica sobre os esboços D936a, limitando-se a reviver as cores antigas e deixando intactas as descontinuidades.

Rendering é tanto orquestração quanto restauração, como a reparação de uma pintura danificada pelo tempo. Quando você vai a Assis, você encontrará belas pinturas de Giotto, algumas das quais estão danificadas. Assim sendo, em vez de tê-las restaurado por algum pintor estúpido que simula ser Giotto e preenche o que está faltando, eles decidiram deixar o branco, o concreto como estava, o que também é muito expressivo. Eu fiz a mesma coisa com Schubert (Berio in MULLER, 1997, p. 19) (tradução nossa) ${ }^{19}$.

Referindo-se ao projeto composicional de Rendering, Berio ressalta o caráter fragmentário desses esboços, sendo tal estado que o atrai. Suas falas evidenciam os danos e as descontinuidades, características tidas como expressivas para sua atuação enquanto compositor. Desse aspecto decorre outro mais

\footnotetext{
$\overline{18}$ Apesar de Berio reconhecer o interesse do maestro pela partitura de Rendering, ele acusa-o de não compreender os princípios de sua restauração. Para o compositor, Harnoncourt fracassou em não perceber a presença artística implícita de Berio na obra, além da sua insatisfação com os tempi mais lentos e com o excesso de vibrato presente nas seções conectivas berianas (cf. BODLEY, 2008, p. 240).

${ }^{19}$ No original: Rendering is both orchestration and a restoration, like the reparation of a painting damaged by time. When you go to Assisi, you will find beautiful Giotto paintings, some of which are damaged. Now instead of having them repaired by some stupid painter who pretends to be Giotto and fills in what is missing, they decided to leave the white, the concrete as it was, which is very expressive too. I did the same thing with Schubert (Berio in MULLER, 1997, p. 19).
} 
profundamente enraizado na poética beriana: a ferrenha crítica àquelas intervenções musicológicas em textos antigos a fim de restabelecê-los na sua integridade, completando-os tal como o compositor poderia ter feito.

Quando redescobertos em 1978, os fragmentos D936a rapidamente despertaram esse tipo de interesse entre musicólogos e compositores ${ }^{20}$. Considerando tais atitudes como pastiches, Berio tece sua crítica aludindo, mais uma vez, à atividade do restauro: "Esta é uma forma curiosa de mimeses que tem algo em comum com aquelas restaurações de quadros às vezes responsáveis por danos irreparáveis, como no caso dos afrescos de Raffaello na Farnesina, em Roma" (BERIO, 2018) (tradução nossa) ${ }^{21}$.

A fala do compositor seguramente condena as "restaurações" empreendidas por Newbould sobre as seis sinfonias inacabadas de Schubert ${ }^{22}$ e expõe mudanças paradigmáticas que direcionaram a Restauração ao longo do século XX na Itália, contexto no qual se desponta a teoria brandiana. O pensamento de Brandi acolheu as aquisições do chamado restauro crítico, advindo no pósSegunda Guerra devido à necessária sistematização dessa atividade em obras e monumentos destruídos por bombardeios e submetidos a inúmeras intervenções irresponsáveis. Sua teoria objeta veementemente os preceitos empíricos, os reduzidos meios teóricos empregados e as decisões guiadas pelo aspecto documental (e não estético) da obra, características que fundamentavam o chamado restauro filológico que dominava essa atividade ao início do século (KÜHL, 2007).

Equiparado à atitude de conclusão de obras inacabadas, Berio (2018) também desaprova o pensamento filológico: "Nunca me senti atraído por aquelas operações de burocracia filológica que, às vezes, levam musicólogos a simularem serem Schubert (se não Beethoven) e a 'completar a Sinfonia tal como o próprio Schubert poderia ter feito'" (tradução nossa) ${ }^{23}$. Essas críticas dirigem-se, sobretudo, àquelas operações que enfatizam a perspectiva documental da obra de arte, desrespeitando as fases pelas quais ela passou e as marcas dessa translação no tempo.

As premissas da restauração crítica de Brandi fundam-se no reconhecimento dialético da historicidade da obra de arte. Entendendo a instância histórica da arte "[...] como produto humano realizado em um certo tempo e lugar e que em certo tempo e lugar se encontra" (BRANDI, 2008, p. 29), tal dialética tornase fundamental na delimitação do campo de atuação da intervenção de restauro. Destarte, Brandi designa três acepções do tempo histórico: a duração da formulação e exteriorização da obra pelo artista; o intervalo entre o término do processo criativo e o momento em que a consciência do fruidor atualiza a obra; e o átimo da revelação da obra na consciência.

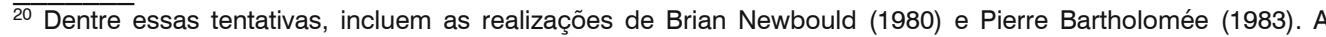
reconstrução de Newbould, por exemplo, está disponível pela coleção Schubert: The 10 Symphonies (cf. NEWBOULD, 1984).

${ }^{21}$ No original: This is a curious form of mimesis that has something in common with those picture restorations sometimes responsible for irreparable damages, as in the case of the Raffaello frescoes at the Farnesina in Rome (BERIO, 2018).

${ }^{22}$ Newbould (1984) propõe "a restauração das obras sinfônicas de Schubert" com o objetivo de completá-las "como o próprio Schubert poderia ter feito".

${ }^{23}$ No original: I have never been attracted to those operations of philological bureaucracy which sometimes lead musicologists to pretend they are Schubert (if not Beethoven) and 'complete the Symphony as Schubert himself might have done' (BERIO, 2018).
} 
Dessa categorização, percebe-se a raiz das críticas acima tecidas:

Claro está que não se poderá falar de restauração durante o período que vai da constituição do objeto à formulação concluída. Se poderá parecer que seja um restauro, dado que a operação acontece sobre uma imagem por sua vez concluída, na realidade, tratar-se-á de uma refusão da imagem em uma outra imagem, de um ato sintético e criativo que desautoriza a primeira imagem e a sela em uma nova (BRANDI, 2008, p. 60).

O teórico italiano denomina tal atitude como restauração fantasiosa, "a mais grave heresia da restauração", aquela que tenta inserir o restauro "exatamente na zelosíssima e não repetível fase do processo artístico" (BRANDI, 2008, p. 60). O autor também declara como absurda a restauração de repristinação, visando extirpar o decurso do tempo entre a conclusão da obra e o presente. Nesse sentido,

[...] o único momento legítimo que se oferece para o ato da restauração é o do próprio presente da consciência observadora, em que a obra de arte está no átimo e é presente histórico, mas é também passado e, a custo, de outro modo, de não pertencer à consciência humana, está na história (BRANDI, 2008, p. 61).

Em Rendering, descartando qualquer atitude reconstrutiva, Berio contemporiza essa dialética histórica reconhecida pelo restauro brandiano. Na peça, destaca-se a poética paradoxal de aproximação e distanciamento da música de Schubert, especialmente quando emergem as seções compostas por Berio, i.e., seu tratamento das lacunas através de um universo sonoro completamente distinto. Bodley (2008, p. 248) considera como crucial as oposições na obra, afirmando que "Rendering é uma montagem de começos e finais, um encontro improvável entre juventude e velhice. A inventividade de Schubert é absorvida por Berio e reformulada dialeticamente em termos modernos" (tradução nossa) ${ }^{24}$.

O âmago de Rendering é justamente a dialética passado-presente. Por um lado, há a cor sonora de Schubert, revivida pela orquestração dos fragmentos D936a e pelo preenchimento de suas vozes internas (BERIO, 2018). Berio segue estritamente as esparsas indicações de instrumentação deixadas nos manuscritos e faz uso da mesma orquestra aplicada por Schubert nas tardias Sinfonia Inacabada (1822) e Grande Sinfonia (1826)

Ademais, há preenchimentos nas vozes internas de alguns trechos da décima sinfonia que remetem à escritura da Sinfonia Inacabada. Um caso emblemático ocorre a partir do quarto compasso do Allegro de Rendering ${ }^{26}$,

\footnotetext{
${ }^{24}$ No original: Rendering is a montage of beginnings and endings, an unlikely bringing together of youth and age. Schubert's inventiveness is taken up by Berio and reformulated dialectically in modern terms (BODLEY, 2008, p. 248).

${ }^{25}$ Possivelmente, sua escolha pautou-se pela utilização de trombones nessas sinfonias, bem como nos esboços D936a. Como o próprio compositor afirma: "Conheço Schubert muito bem porque lhe fiz uma espécie de 'operação' cerebral para entender como ele teria realizado a orquestração" (BERIO, 2013, p.453-54).

${ }^{26}$ Berio não faz uso da numeração de compassos na obra, somente cifras de ensaio.
} 
primeira inserção contrapontística de Berio em que uma figuração regular de semicolcheias é incorporada às cordas. Funcionando como motor rítmico de todo o movimento, esse padrão de preenchimento reporta-se à escritura dos violinos na Sinfonia Inacabada, tema principal do Allegro moderato (Figura 2).
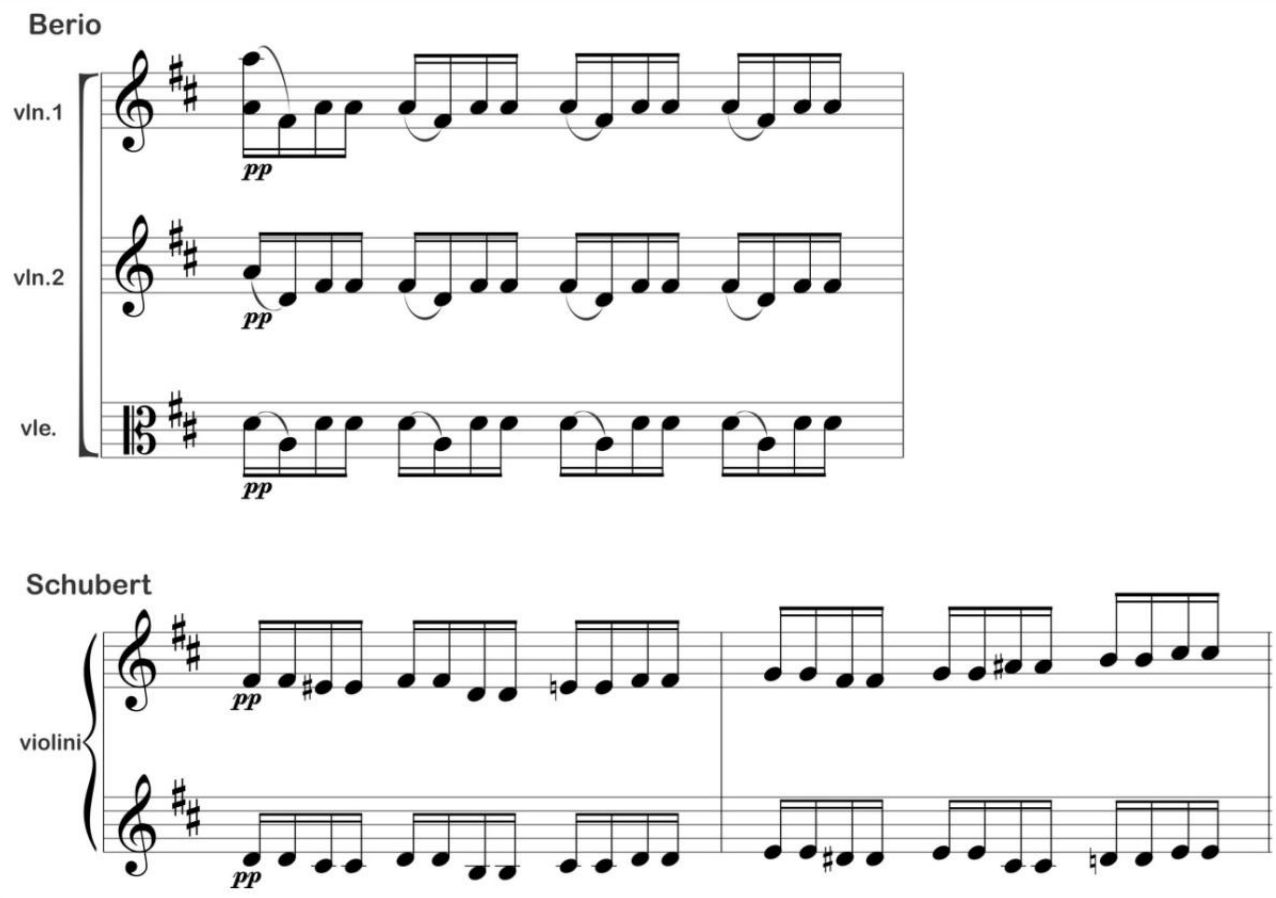

Figura 2. Preenchimento contrapontístico incorporado em Rendering e, abaixo, o motor rítmico da Sinfonia Inacabada de Schubert. Fonte: o autor.

Por outro lado, embora a manutenção das cores originais aluda ao universo schubertiano, essa experiência sinfônica hesita quando emergem as lacunas. "Berio não suprime esses espaços nem os conecta com preenchimento estilisticamente apropriado, como poderia ser feito em uma conclusão, mas, ao contrário, deixa-os intactos e adiciona seu próprio material" (METZER, 2000, p. 98) (tradução nossa) ${ }^{27}$.

Evitando uma intervenção fantasiosa, a atitude de Berio aproxima-se da máxima brandiana:

A restauração, para representar uma operação legítima, não deverá presumir nem o tempo como reversível, nem a abolição da história. A ação de restauro, ademais, e pela mesma exigência que impõe o respeito da complexa historicidade que compete à obra de arte, não se deverá colocar como secreta e quase fora do tempo, mas deverá ser pontuada como evento histórico tal como o é [...] (BRANDI, 2008, p. 61).

\footnotetext{
${ }^{27}$ No original: Berio neither erases those spaces nor plugs them in with stylistically appropriate filler, as may be done in a completion, but instead leaves them intact and adds his own material (METZER, 2000, p. 98).
} 
Os lapsos no tecido de Schubert foram tratados por um "delicado cimento musical que comenta as descontinuidades e as lacunas entre um rascunho e outro" (BERIO, 2018) (tradução nossa) ${ }^{28}$. Seu restauro, visando o restabelecimento da unidade potencial sem cometer falso artístico e falso histórico, propõe uma metodologia muito próxima à indicada por Brandi: "dar à lacuna uma coloração que, em vez de se harmonizar ou de não exceder nas cores da pintura, se destaque violentamente no tom e na luminosidade, se não no timbre" (BRANDI, 2008, p. 50).

A Teoria de Brandi objeta a utilização de uma argamassa neutra, visando manter intata a distribuição cromática original e o jogo de tensões entre fragmentos e lacunas (cf. Figura 3). Impedindo que esse material componha-se com as cores originais, "a lacuna, com efeito, terá uma forma e uma cor, não relacionadas com a figuratividade da imagem representada. Insere-se, em outras palavras, como corpo estranho" (BRANDI, 2008, p. 49).

Osmond-Smith (1993, p. 80) confirma tal abordagem de Berio ao pontuar que, em suas seções, "o preenchimento ou 'renderização' (um dos vários significados possíveis de seu dúbio título) não é, todavia, o equivalente musical à argamassa neutra" (tradução nossa) ${ }^{29}$.

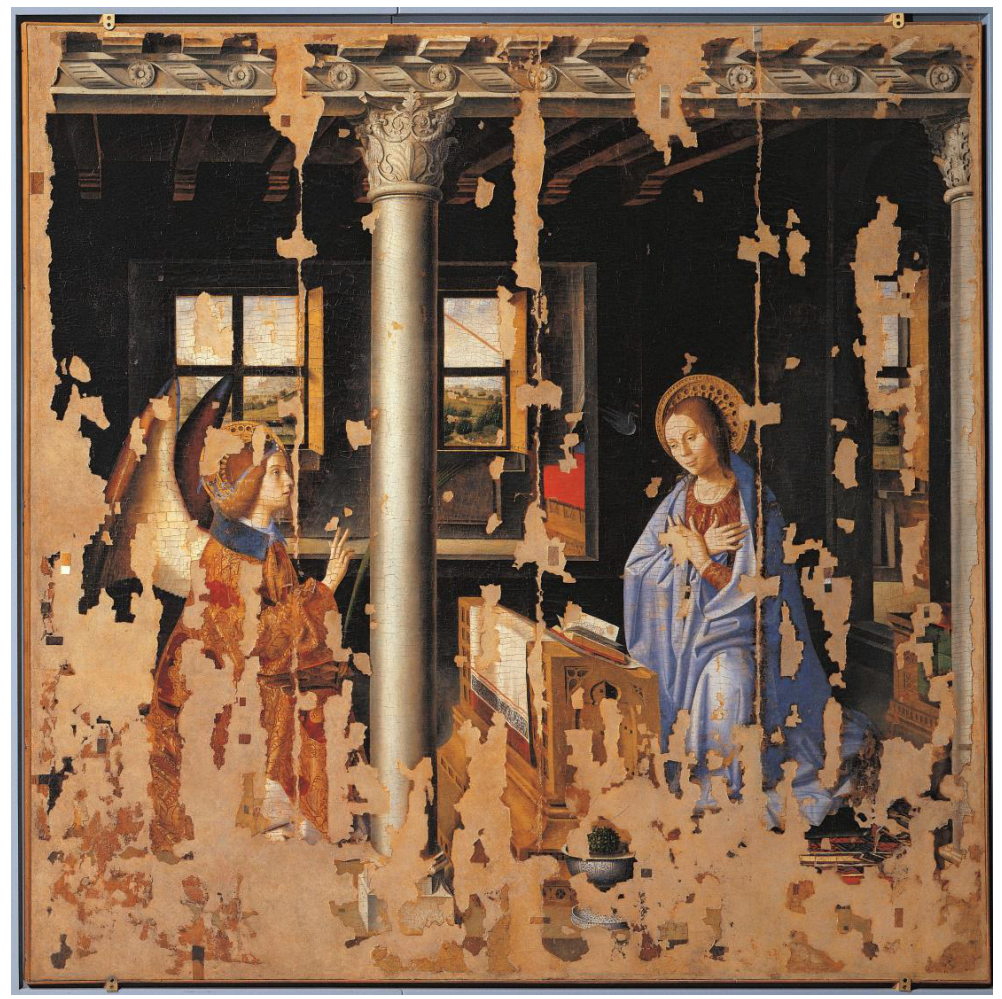

Figura 3. Restauro de Brandi sobre Anunciação (1474), Antonello da Messina. Fonte: https://restaurars.altervista.org/cesare-brandi-e-i-restauri-delli-c-r/.

\footnotetext{
${ }^{27}$ No original: delicate musical cement that comments on the discontinuities and the gaps between one sketch and the other (BERIO, 2018).

${ }^{29}$ No original: the filling or 'rendering' (one of several possible meanings for his punning title) is not however the musical equivalent of neutral plaster (OSMOND-SMITH, 1993, p. 80).
} 


\section{A argamassa musical aplicada às lacunas da décima sinfonia de Schubert}

A argamassa beriana é sempre anunciada pela celesta, instrumento inexistente na época de Schubert ${ }^{30}$ e cuja sonoridade prontamente institui um universo distante à sua música. Ao contrário da imponência sinfônica, essas intervenções conectivas soam em pianíssimo e distantes, constantemente diferentes e mutáveis (BERIO, 2018).

No decorrer do Allegro de abertura, tal cimento musical ocupa cerca de um terço do movimento. São duas aparições desse tecido beriano entrelaçando três seções schubertianas. Essas últimas são baseadas nas duas versões elaboradas para o primeiro movimento da décima sinfonia. Assim, Berio incorpora tanto rascunhos incipientes, ou mesmo abandonados e rabiscados por Schubert quanto os esboços mais bem concluídos, muitos reelaborados.

Todavia, o compositor não manipula os manuscritos conforme a ordem notada, estabelecendo um plano formal que contrapõe diferentes tentativas de uma mesma ideia musical. Essa atitude frente ao texto de Schubert almeja a manutenção do caráter fragmentário da décima sinfonia, não cometendo um falso histórico revertendo sua incompletude, tampouco uma ofensa artística buscando uma restauração fantasiosa.

Em linhas gerais, o plano formal trabalhado por Berio no primeiro movimento lida com todos os materiais compostos por Schubert para o Allegro D936a. A primeira seção beriana conecta duas tentativas de uma exposição, iniciando-se com a segunda versão, mais bem acabada e demarcada por Anfang. A segunda interpolação de Berio concatena tais versões da exposição à seção de desenvolvimento escrita em andamento Andante, seguida da coda em Presto. A Figura 4 apresenta as subdivisões formais do Allegro de Rendering e a demarcação dos fragmentos schubertianos selecionados.

\begin{tabular}{|c|c|c|c|c|c|}
\hline & Schubert & Berio & Schubert & Berio & Schubert \\
\hline cifras & $0-5$ & $6-11$ & $12-23$ & $24-30$ & $31-37$ \\
\hline caráter & Allegro & $\begin{array}{l}\text { Molto lontano, } \\
\text { non "cantare"! }\end{array}$ & [Allegro] & $\begin{array}{l}\text { Molto lontano, } \\
\text { mormorando }\end{array}$ & $\begin{array}{l}\text { Pochissimo meno } \\
\text { (Andante - Presto) }\end{array}$ \\
\hline $\begin{array}{r}\text { natureza do } \\
\text { material }\end{array}$ & $\begin{array}{l}2^{\mathrm{a}} \text { exposição } \\
\text { Tema principal e } \\
\text { Transição (oboé) }\end{array}$ & & $\begin{array}{c}1^{\mathrm{a}} \text { exposição } \\
\text { Tema principal } \\
\text { Tema Secundário } \\
\text { (violoncelos) }\end{array}$ & & $\begin{array}{c}\text { Desenvolvimento } \\
\text { (trombones) } \\
\text { Coda }\end{array}$ \\
\hline
\end{tabular}

Figura 4. Plano formal do primeiro movimento de Rendering. Fonte: o autor.

$\mathrm{Na}$ primeira interpolação de Berio, a argamassa rapidamente dilui a sonoridade schubertiana, mantendo somente dois elementos que originam diretamente de sua escritura. De um lado, tem-se a manutenção de figuras

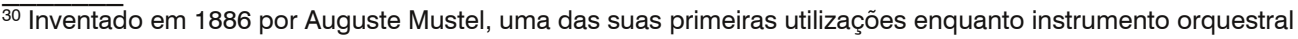
reporta-se à La tempête (1888) de Ernest Chausson (BLADES; HOLLAND, 2001).
} 
motivicamente derivadas dos esboços $\mathrm{D} 936 \mathrm{a}$, como os grupos de semicolcheias baseadas no motor rítmico adicionado por Berio e as figuras pontuadas derivadas do tema principal (Figura 5).

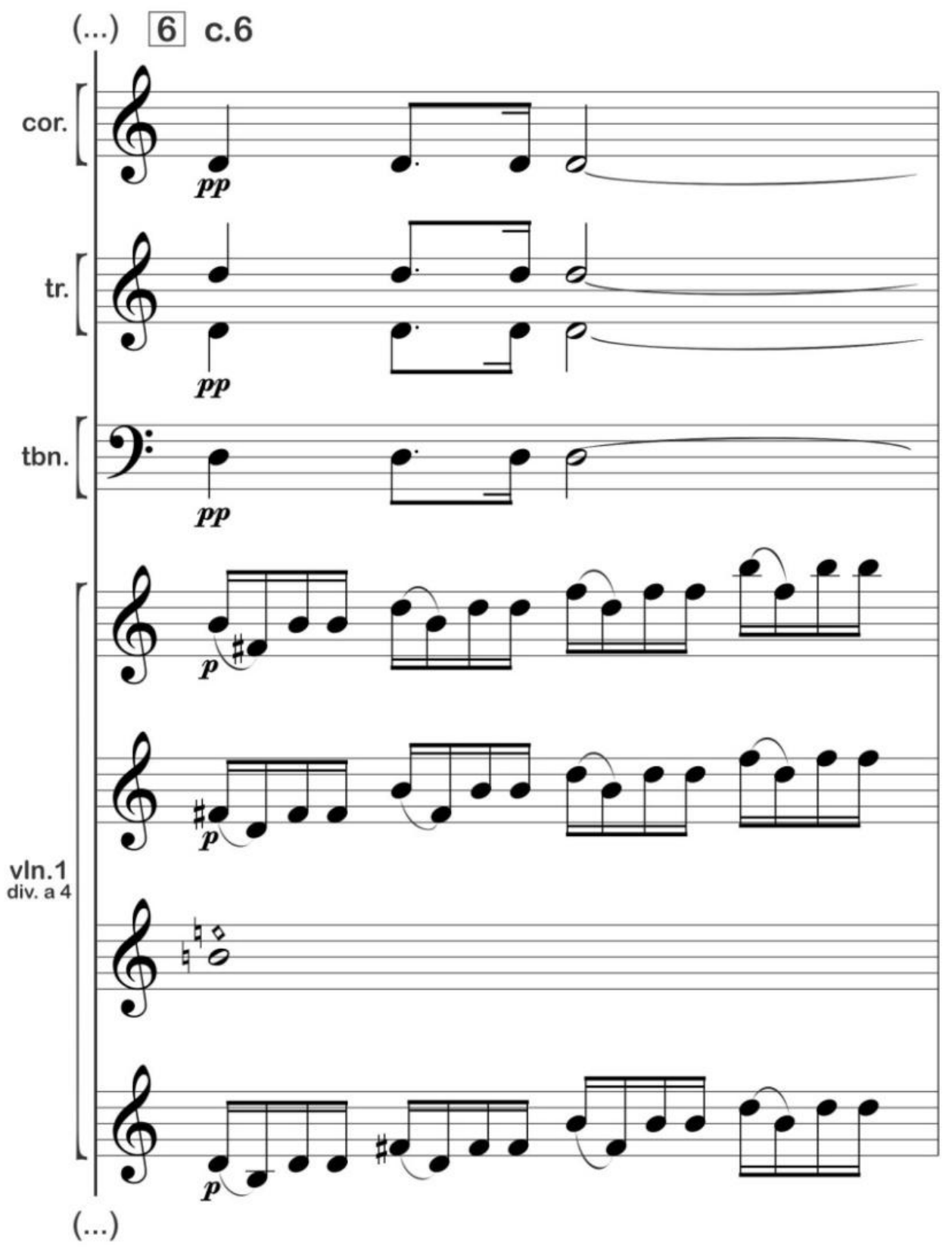

Figura 5. Materiais musicais da primeira argamassa beriana derivados dos esboços D936a. Fonte: Adaptado de Berio (1989). 
Por outro lado, Berio incorpora "citações" de obras tardias de Schubert. Essas reminiscências (BERIO, 2018) são mais presentes no primeiro movimento e boa parte delas advém da Sonata em Sib (D960), do Trio em Sib (D898) e do ciclo de canções Winterreise (D911) ${ }^{31}$. Executados quase inexpressivamente (non 'cantare'), esses elementos adensam ainda mais a polifonia orquestral molto lontana ${ }^{32}$, sobretudo entre as cifras 8 e 9 . A Figura 6 reúne algumas dessas citações que emergem na primeira argamassa beriana.

Sonata D960, I mov.

vin.

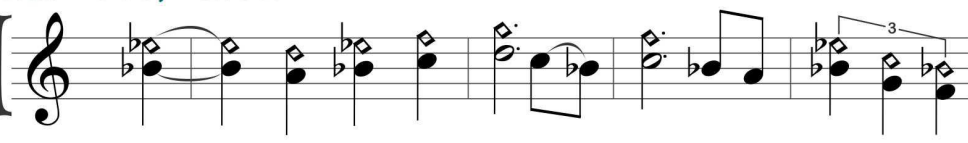

9 c. $2-6$

Sonata D960, III mov.

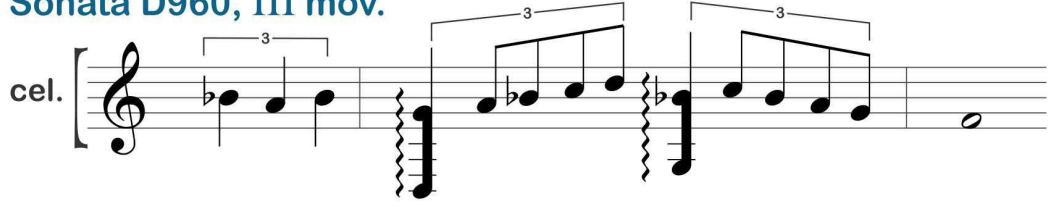

8 c. $7-8$

Gute Nacht: Winterreise D911

fl.

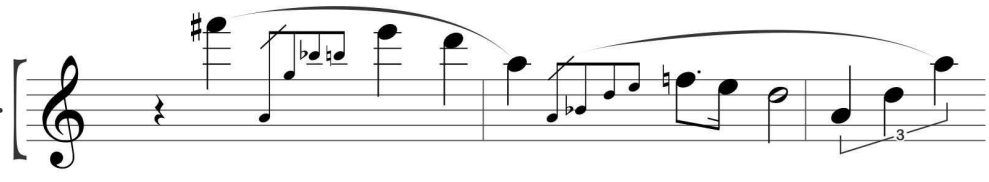

8 c.4-6

Figura 6. Reminiscências da Sonata em Sib D960 e do Lied Gute Nacht D911 no primeiro movimento de Rendering. Fonte: o autor.

As conexões berianas, ricamente polifônicas e constituídas por delicadas linhas em pianíssimo, fundamentam-se em processos harmônicos que revelam alguns dos seus principais traços escriturais. Uma redução dessa textura demonstra campos altamente esparsos no registro, a partir dos quais afloram os fragmentos melódicos da massa orquestral.

Berio constitui aglomerados de distintas densidades harmônicas, encadeados ao longo desse tecido por meio da exploração de notas-pivô, de conduções lineares entre suas componentes e de alturas polarizadas no registro. Essas estratégias advêm de sua preocupação com a percepção dos processos, resultando em um fluxo harmônico mutável no qual as notas "congeladas" geram redundâncias entre os distintos acordes, as novas notas surgem por deslocamentos em graus conjuntos e as alturas polarizadas criam centros de referências harmônicas.

$\mathrm{Na}$ Figura 7, tais traços são destacados por cores em um trecho da argamassa que parte de amplos agregados, os quais se polarizam, paulatinamente,

\footnotetext{
${ }_{31}$ Para maiores detalhes, cf. Gruhn (1990).

32 Vale ressaltar que Berio, em suas interpolações, modifica a escrita orquestral, dividindo o naipe das cordas em instrumentos solistas (violinos em divisi a 4; violas, violoncelos e contrabaixos em divisi a 2). De acordo com Osmond-Smith (1993, p. 81), nesses trechos ocorre uma expansão em nuvem divisi.
} 
em Fá\#; esse centro, então, baliza alternâncias entre uníssonos e acordes mais complexos. Conforme Menezes (2015), a frequente oposição entre uníssonos e aglomerados de alturas mostra-se como outro traço distintivo da poética beriana, vinculado à questão da verbalidade (i.e., a oposição hegemônica das línguas entre vogal e consoante) e que impregna quase toda a obra do compositor italiano.
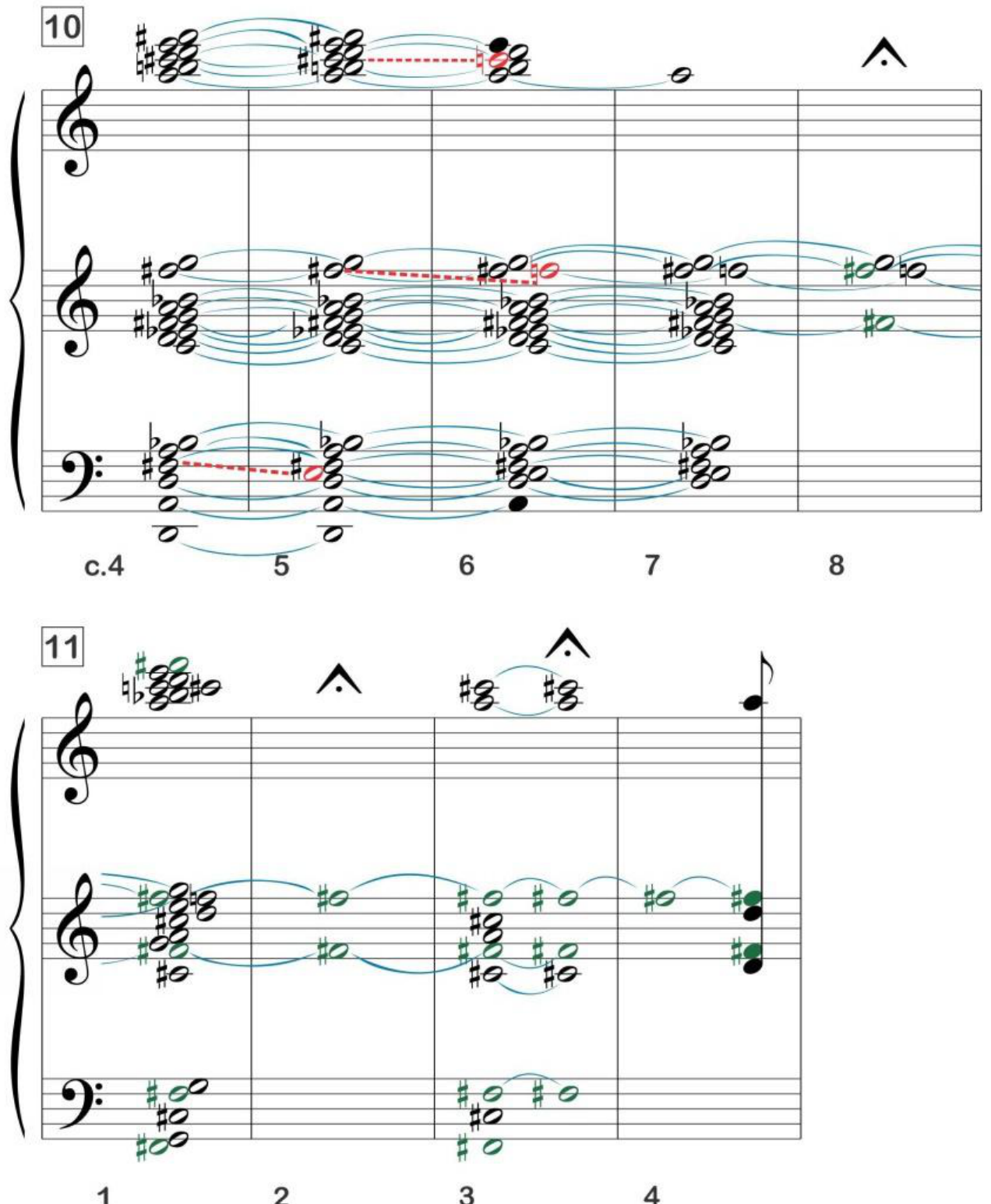

Figura 7. Estratégias de encadeamento entre distintos campos harmônicos na argamassa beriana. Fonte: o autor. 
Em termos gerais, a primeira conexão apresenta clara direcionalidade, a despeito de sua perspectiva harmônica constantemente mutável. As extrapolações lineares que conformam a textura dessa argamassa são governadas por uma sequência de campos harmônicos, outra estratégica típica da escritura de Berio, inter-relacionada ao seu entendimento processual da forma enquanto formação dos materiais e que perpassa boa parte da sua produção musical ${ }^{33}$.

Ante sua função conectiva, é possível organizar esse tecido em quatro momentos: (1) parte de uma sonoridade que dá continuidade aos fragmentos schubertianos, pois o campo harmônico ao início da cifra 6 polariza-se em Lá Maior, possível região de cadência caso não houvesse a lacuna no trecho; (2) não tarda para que a linha do baixo estabeleça uma progressão descendente que atinge três oitavas sob campos harmônicos com referências tonais, dos quais se desprendem as demais figuras (até final da cifra 7); (3) em meio às formações harmônicas baseadas na mesma fundamental Ré (até o final da cifra 9), emergem diversas reminiscências de obras tardias de Schubert, alcançando clara densificação da textura orquestral; (4) o tecido progressivamente detém-se em longos trinados e as figurações escasseiam-se, restando agregados que demonstram forte polarização em Fá\#, nota que se tornará pivô para o retorno dos fragmentos D936a e, consequentemente, da notável sonoridade schubertiana (Figura 8).

\footnotetext{
$\overline{33}$ Este é o caso da série Sequenze (1958-2002), cujo título sugere um discurso harmônico melodicamente desenvolvimento, a partir do qual as outras funções musicais são derivadas.
} 
6

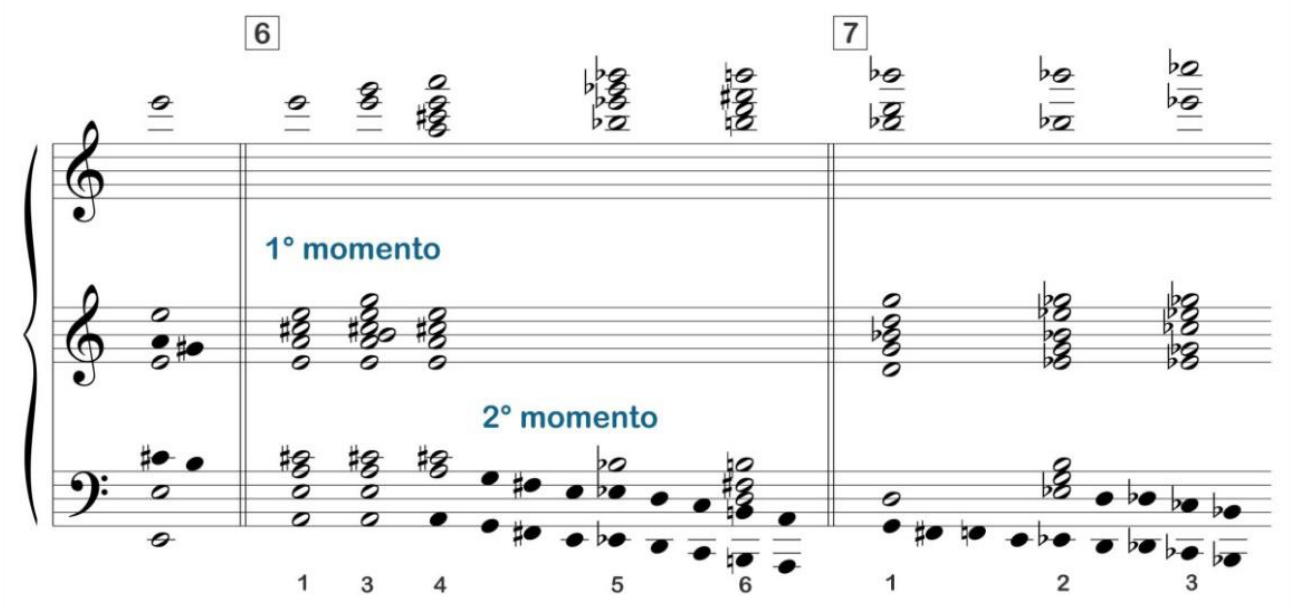

188
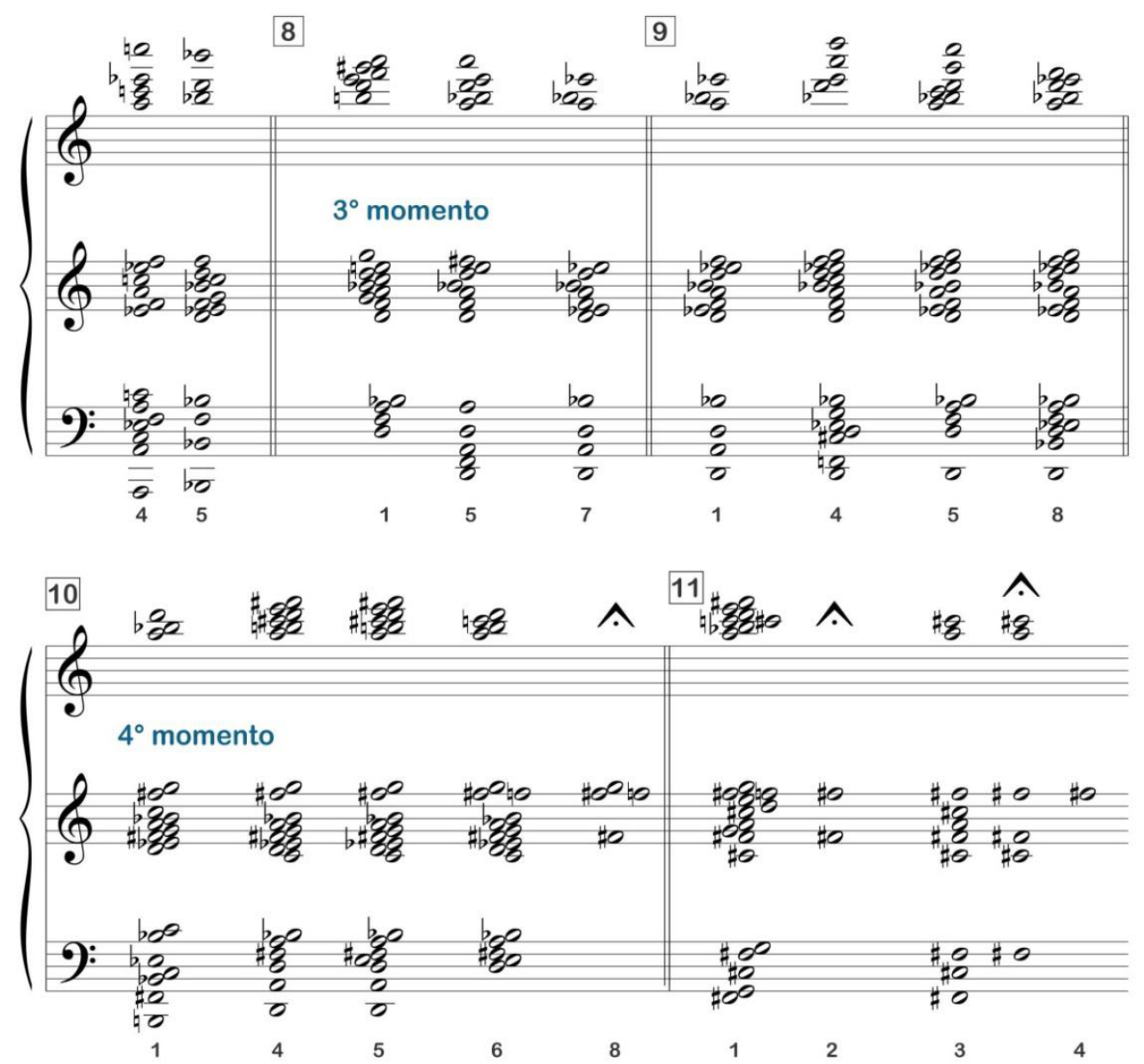

Figura 8. Redução da primeira argamassa conectiva e sua estruturação em quatro momentos. Fonte: 0 autor. 


\section{Considerações Finais}

Investigando o processo composicional de Rendering a partir da alusão ao restauro dos afrescos de Giotto em Assis, esse estudo detectou interessantes paralelos entre a abordagem composicional de Berio e os princípios da Teoria da Restauração de Brandi. As análises dos procedimentos escriturais da peça demonstraram que o restauro da décima sinfonia de Schubert reflete uma das máximas da teoria brandiana: não se pode inverter o curso do tempo e inserir-se com legitimidade naquele momento em que o artista estava criando a obra de arte. Para o autor, a única postura plausível no ato do restauro é considerar a obra em sua presença atual que se faz realidade em nossa consciência (BRANDI, 2008).

Essa poética paradoxal é traço primordial da obra beriana. Em Rendering, sua consciência histórica da música de Schubert é expressa pela própria prática composicional: através do minucioso restauro das cores schubertianas, da exploração dos caracteres que o distanciavam de Beethoven e, especialmente, do diálogo realizado com outras obras do mestre vienense. Por outro lado, a peça é carregada de traços atuais, sobretudo pela presença de Berio nas seções conectivas, nas quais afloram uma sonoridade ímpar devido ao tratamento harmônico, textural e tímbrico.

Embora as poéticas musicais de vanguarda no pós-Segunda Guerra ansiaram utopicamente pela transcendência da história, visando galgar uma condição distinta naqueles tempos assoladores, Berio caminhou em sentido oposto aos seus colegas de Darmstadt. Rendering é um grande exemplo desse trajeto no qual o mestre italiano dialoga substancialmente com os principais movimentos artísticos do século XX, sem deixar de experimentar incursões na história da música.

\section{REFERÊNCIA}

BERIO, Luciano. Berio: Two Interviews with Rossana Dalmonte and Bálint András Varga. New York: Marion Boyars, 1985.

. Rendering [partitura]. Viena: Universal Edition, 1989.

Remembering the Future. Cambridge: Harvard University Press, 2006.

Scritti sulla musica. A cura di Angela Ida de Benedictis. Turim: Einaudi, 2013.

. Interviste e colloqui. A cura di Vincenzina C. Ottomano. Turim: Einaudi, 2017.

Rendering(autor's note). Disponível em:

<http://www.lucianoberio.org/node/1448?1304392085=1>. Acesso: 03 ago. 2018.

BLADES, James; HOLLAND, James. Celesta. Oxford Music Online, 2001.

BODLEY, Lorraine. Late style and the paradoxical poetics of the Schubert-Berio Renderings. In: REUL, B.; BODLEY, L. The Unknown Schubert. Ashgate, p.233-249. 2008. 
BRANDI, Cesare. Teoria da Restauração. 3. ed. Cotia: Ateliê Editorial, 2008.

GRIFFEL, L. Michael. A Música Orquestral de Schubert: "A Busca pelo Mais Elevado em Arte”. In: GIBBS, C. (Org.). Schubert: Um Compêndio. São Paulo: Edusp, 2017. p.257-272.

GRUHN, Wilfried. Playing Schubert: Berio's symphonic additions to Schubert's symphony fragmente D.936a. Musica, v.44, n.5, p.290-296. 1990.

KÜHL, Beatriz. Cesare brandi e a teoria da restauração. Revista Pós, n.21, p.198-211. 2007.

MENEZES, Flo. Apoteose de Schoenberg: tratado sobre as entidades harmônicas. 2. ed. São Paulo: Ateliê, 2002.

(Org.). Luciano Berio: legado e atualidade. São Paulo: Editora Unesp Digital, 2015.

METZER, David. Musical Decay: Luciano Berio's Rendering and John Cage's Europera 5. Journal Of The Royal Musical Association, v.125, n.1, p.93-114. 2000.

MULLER, Theo. 'Music is not a solitary act': conversation with Luciano Berio. Tempo, v.3, n.199, p.16-20. 1997.

NEWBOULD, Brian. The restoration of Schubert's Symphonic Works. Encarte. Schubert: The 10 Symphonies. Philips, 1984.

Recebido em 11/09/2018 - Aprovado em 03/04/2019

Como citar:

Miranda, P. (2019). Luciano Berio, restaurador: análise de Rendering Per orchestra (1988-90). OuvirOUver, 15(2), 172-190. https://doi.org/10.14393/OUV24-v15n1a2019-12

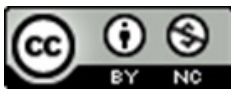

A revista ouvirOUver está licenciada com uma Licença Creative Commons Atribuição-NãoComercial 4.0 Internacional. 